\title{
Effect of sex and gestational age on neonatal body composition
}

\author{
Laure Simon ${ }^{1} \dagger$, Paula Borrego ${ }^{2} \dagger$, Dominique Darmaun ${ }^{2}$, Arnaud Legrand ${ }^{3}$, Jean-Christophe Rozé $e^{1,2,3 *}$ \\ and Anne Chauty-Frondas ${ }^{1,2,3}$ \\ ${ }^{1}$ Department of Neonatal Medicine, Hôpital Mère-et-Enfant, CHU de Nantes, 44093 Nantes cedex 1, France \\ ${ }^{2}$ INRA UMR 1280, Physiologie des Adaptations Nutritionnelles, Université de Nantes, CRNH, Nantes, IMAD, \\ CHU de Nantes, France \\ ${ }^{3}$ Centre d'Investigation Clinique INSERM, CICOO4 CHU de Nantes, France
}

(Submitted 30 November 2011 - Final revision received 31 May 2012 - Accepted 1 June 2012 - First published online 12 July 2012)

\section{Abstract}

To determine the effects of length of gestation and sex on infant body composition, air displacement plethysmography was performed in forty-six full-term neonates at $3 \mathrm{~d}$ of life and during the week prior to hospital discharge in 180 preterm neonates. Fat mass, as a percentage of body weight, was higher in preterm than in term infants (13.4 (SD 4.2) $v \cdot 10 \cdot 1$ (sD 3.7) \%, respectively; $P=0 \cdot 001$ ). The absolute amount of fat mass did not differ between preterm and full-term newborns (323 (SD 126) $v .335$ (SD 138) g; $P=0 \cdot 58$ ), whereas lean body mass was lower in preterm than in term infants (2055 (SD 280) v. 2937 (SD 259) g, respectively; $P<0 \cdot 001$ ). Among full-term infants, fat mass was higher in females than in males (11.1 ( $\mathrm{SD} 3.7) v .9 .0$ ( $\mathrm{SD} 3.3$ ) \%, respectively; $P=0.047$ ), whereas we did not observe any sex difference in preterm infants $(13.5$ (SD 4.1$) v .13 .4$ (SD 4.3$) \% ; P=0.89)$. Our data suggest that by the time they are discharged from hospital: (1) preterm infants have a higher percentage of body fat than term neonates and (2) this is presumably due to a lesser accretion in lean body mass in the first few weeks of extra-uterine life, particularly in boys.

Key words: Sex differences: Preterm infants: Newborn infants: Body composition: Fat mass: Lean body mass

Throughout life, fat mass is higher in females than in males. This holds true for full-term newborn infants ${ }^{(1-3)}$. Whether this is true in preterm infants is unknown. Besides, adults born with a very low birth weight are less sensitive to insulin and are at higher risk of developing $\mathrm{CVD}^{(4,5)}$, and fat mass accretion contributes to the pathophysiology of insulin resistance $^{(6)}$. As nutritional status early in life may determine the risk of chronic disease in adulthood, differences in neonatal body composition in early life may contribute to differences in outcome between males and females and also between term and preterm infants. It is therefore urgent to improve our understanding of term- and sex-related differences in body composition in the first few weeks of life. The aim of the present study was to determine the impact of term of birth and sex on infant body composition at the time of hospital discharge.

\section{Materials and methods}

We conducted a prospective, observational study among two groups of infants admitted to Nantes University Hospital: (1) full-term neonates with a birth weight above the 10th percentile of Olsen's curves born between February and April 2009 and (2) preterm neonates with less than 35 weeks of gestation, born between January 2009 and August 2011. Exclusion criteria were presence of congenital disease, unstable medical status at discharge and parent's refusal to participate. The present study was conducted according to the guidelines laid down in the Declaration of Helsinki and all procedures involving human patients were approved by the Nantes Ethics Committee (Groupe Nantais d'Ethique dars le Domaine de la Santé; GNEDS). Verbal informed consent was obtained from all parents. Verbal consent was witnessed and formally recorded. The trial was registered at www.clinicaltrials.gov, under identifier no. NCT00890344.

Premature infants with no respiratory distress and with a birth weight higher than $1800 \mathrm{~g}$ were immediately fed through a nasogastric tube with maternal milk or preterm formula $(2 \mathrm{~g}$ protein $/ 100 \mathrm{ml})$ at a rate of $70 \mathrm{ml} / \mathrm{kg}$ per $\mathrm{d}$. The rest of the preterm infants received parenteral nutrition at the initial rate of $80 \mathrm{ml} / \mathrm{kg}$ per $\mathrm{d}$, increased to $160-180 \mathrm{ml} / \mathrm{kg}$ per $\mathrm{d}$ on the 6th day. For parenterally fed infants, amino acids were started at $1.5 \mathrm{~g} / \mathrm{kg}$ per $\mathrm{d}$ on the 1 st day and increased up to $3.5-4.0 \mathrm{~g} / \mathrm{kg}$ per $\mathrm{d}$ on the 4 th day. Parenteral nutrition was

*Corresponding author: Professor J.-C. Rozé, fax +332534820 03, email jcroze@chu-nantes.fr

†These authors contributed equally to the present work. 
discontinued once enteral intake reached $140 \mathrm{ml} / \mathrm{kg}$ per d. Infants below $1500 \mathrm{~g}$ received human milk supplemented with $20-30 \mathrm{~g} / 1$ Eoprotine ${ }^{\circledR}$ (Milupa). Once their weight reached $1500 \mathrm{~g}$, infants were fed formula if mothers declined to breastfeed. We used a preterm formula containing $2.9 \mathrm{~g}$ protein $/ 100 \mathrm{ml}$ until the body weight reached $2000 \mathrm{~g}$, and a formula with $2 \mathrm{~g}$ protein $/ 100 \mathrm{ml}$ thereafter.

On the 5th, 10th and 21st day of hospitalisation, the daily volume of milk or formula and parenteral feeding prescribed for each individual premature baby was recorded. The enteral, intravenous and overall glucose, protein, lipid and energy intake (expressed in $\mathrm{g}$ or $\mathrm{kJ} / \mathrm{kg}$ per $\mathrm{d}$ ) was calculated based on the volumes prescribed, the nutrient content of formula and parenteral admixtures (as reported by the formula manufacturer and the hospital pharmacists, respectively) and on the daily measured infant weight. For infants receiving human milk, we assumed the milk macronutrient content to be the average macronutrient content of human milk collected at the hospital human milk bank. Anthropometric parameters and body composition were assessed at $3 \mathrm{~d}$ of life for full-term newborns and during the week before discharge for preterm infants. Body weight was measured twice on an electronic scale accurate to the nearest $0 \cdot 1 \mathrm{~g}$ and the mean value was used. It was expressed as a $Z$ score in reference to Olsen's curves. Body length was determined using a graduated ruler and head circumference with a non-stretch measuring tape. Body composition was assessed by air displacement plethysmography (PEA POD ${ }^{\circledR}$, COSMED) ${ }^{(7)}$. Measurements were performed in duplicate by the same operator, a doctor of the neonatal intensive care unit.

Descriptive data are expressed as mean and standard deviation. Differences in measured fat mass between groups were assessed by ANOVA. Statistical significance was set at $\alpha=0 \cdot 05$. Nutrient intake during hospital stay was expressed as median and range in percentiles (25th-75th), and comparisons were performed using non-parametric tests (MannWhitney). All statistical analyses were performed using SPSS $^{\circledR}$ software (SPSS, version 19; SPSS, Inc.).

\section{Results}

Forty-six full-term infants (twenty-four boys) and 180 preterm infants (eighty-seven boys) were enrolled. Selected clinical characteristics of the infants are reported in Table 1.

For preterm infants, protein and energy intake was 2.6 $(2-3 \cdot 4) \quad v .2 \cdot 4(1 \cdot 8-3 \cdot 2) \mathrm{g} / \mathrm{kg}$ per $\mathrm{d}(P=0 \cdot 09)$ and 401 $(342-472)$ v. $376(330-439) \mathrm{kJ} / \mathrm{kg}$ per $\mathrm{d}(P=0 \cdot 11)$ in girls and boys, respectively, on day 5 ; and $3 \cdot 2(2 \cdot 9-3 \cdot 4) v .3$ $(2 \cdot 3-3.4) \mathrm{g} / \mathrm{kg}$ per $\mathrm{d}(P=0.01)$ and $505(468-535) \quad v .472$ $(447-505) \mathrm{kJ} / \mathrm{kg}$ per d at day $21(P=0 \cdot 001)$. The length of stay in the neonatal unit tended to be longer in female than male preterm infants (51 (SD 27) v. $43(\mathrm{SD} 26) \mathrm{d} ; P=0.06)$, but the duration of respiratory support (18 (SD 26) $v .15(\mathrm{SD} 24) \mathrm{d} ; P=0 \cdot 44)$ or parenteral nutrition (13 (SD 18) v. $11(\mathrm{SD} 18) \mathrm{d} ; P=0 \cdot 35) \mathrm{did}$ not differ. Growth deficit was observed between birth and discharge with a loss (negative change) in weight $Z$ score using Olsen's curves ( -0.88 (sD 0.75) $Z$ score). The degree of extra-uterine growth retardation did not differ between girls $(-0.94(\mathrm{SD} 0.8))$ and boys $(-0.82(\mathrm{sD} 0.62))(P=0.29)$.

Full-term infants had a significantly lower percentage of fat mass than preterm infants (10.1 (SD 3.7) v. 13.4 (SD 4.2)\%; $P<0.001$ ) (Fig. 1). Among full-term infants, fat mass percentage was higher in females than in males (11.1 (SD 3.7) $v$. $9 \cdot 0$ (SD 3.3) \%; $P=0.047$ ), whereas we did not observe any sex difference in preterm newborns (13.5 (SD 4.1) v. 13.4 (SD 4.3) $\% ; P=0.89$ ). Moreover, the absolute amount of fat mass did not differ between preterm and full-term newborns (323 (SD 126) v. 335 (SD 138) g; $P=0.58$ ), whereas lean body mass was lower in preterm (2055 (SD 280) g) than term infants (2937 (sD 259) g; $P<0 \cdot 001$ ).

\section{Discussion}

Consistent with earlier studies ${ }^{(8,9)}$, the present study confirms the higher accretion of fat mass, and lesser accretion of lean body mass in preterm babies at the time of discharge, compared with term infants. Whether the higher percentage of fat mass is a primary phenomenon or is secondary to the

Table 1. Clinical characteristics of the population

(Mean values and standard deviations)

\begin{tabular}{|c|c|c|c|c|c|c|c|c|}
\hline & \multicolumn{4}{|c|}{ Full-term infants ( $n$ 46) } & \multicolumn{4}{|c|}{ Preterm infants ( $n$ 180) } \\
\hline & \multicolumn{2}{|c|}{ Females ( $n$ 22) } & \multicolumn{2}{|c|}{ Males ( $n$ 24) } & \multicolumn{2}{|c|}{ Females ( $n 93)$} & \multicolumn{2}{|c|}{ Males ( $n 87)$} \\
\hline & Mean & SD & Mean & SD & Mean & SD & Mean & SD \\
\hline \multicolumn{9}{|l|}{ At birth } \\
\hline Gestational age (weeks) & $40 \cdot 3$ & 0.9 & $40 \cdot 0$ & 0.9 & $31 \cdot 2$ & $2 \cdot 8$ & 31.7 & 2.4 \\
\hline Weight (g) & 3345 & 321 & 3551 & 343 & 1410 & 484 & 1645 & 501 \\
\hline Length $(\mathrm{cm})$ & 48.9 & 1.7 & 49.7 & 1.9 & 38.6 & 4.4 & 40.7 & 3.9 \\
\hline Head circumference $(\mathrm{cm})$ & $34 \cdot 1$ & 0.8 & 35.4 & 1.6 & $27 \cdot 5$ & $2 \cdot 8$ & $28 \cdot 7$ & $2 \cdot 6$ \\
\hline \multicolumn{9}{|c|}{ At the time of body composition determination } \\
\hline Postnatal age (weeks) & 0.4 & 0.1 & 0.4 & 0.2 & $6 \cdot 8$ & 3.7 & $6 \cdot 0$ & 3.6 \\
\hline Postmenstrual age (weeks) & 40.7 & 0.9 & $40 \cdot 4$ & 1.0 & 37.9 & 1.6 & 37.7 & 1.9 \\
\hline Weight (g) & 3166 & 315 & 3360 & 328 & 2271 & 289 & 2492 & 349 \\
\hline Length $(\mathrm{cm})$ & $48 \cdot 9$ & 1.7 & 49.7 & 1.9 & $44 \cdot 3$ & 1.8 & 45.5 & $2 \cdot 1$ \\
\hline Head circumference $(\mathrm{cm})$ & 34.1 & 0.8 & 35.4 & 1.6 & 32.4 & $1 \cdot 1$ & 33.0 & 1.1 \\
\hline
\end{tabular}




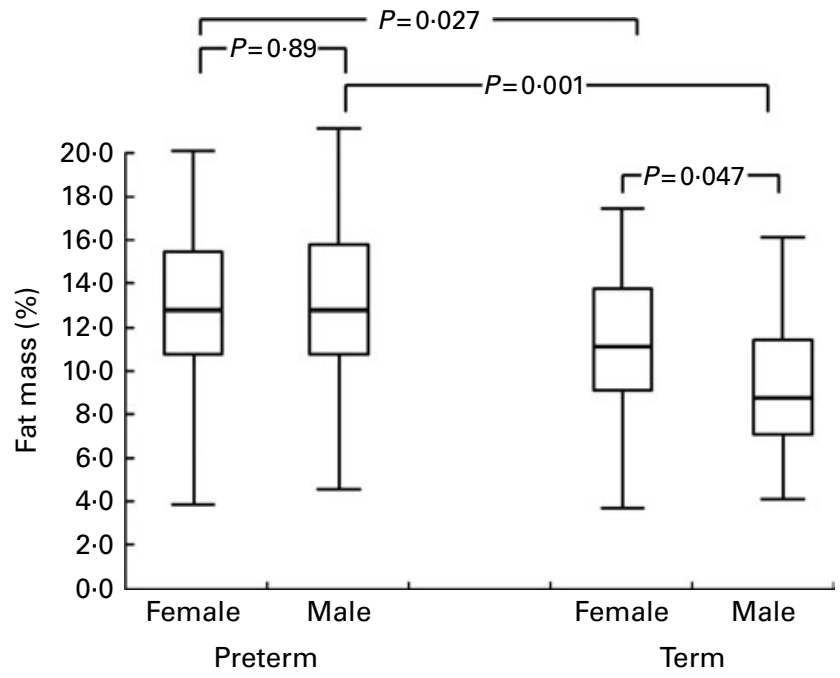

Fig. 1. Fat mass percentage in term and preterm infants, according to infant sex.

lesser accretion of lean body mass cannot be ascertained from our data. In addition, to the best of our knowledge, the present study was the first to address the additional issue of sex differences in response to inadequate early nutrition.

In the present study, body composition was not assessed at the same gestational age in preterm ( 37 weeks) and term infants ( 40 weeks). Fat mass, however, is known to increase steadily during the first few months of postnatal life, from about $10 \%$ at birth to about $26 \%$ at 6 months of age in term infants $^{(1)}$. So, the different timing of measurement could underestimate the difference of percentage of fat mass between preterm and term babies. The fact that fat mass percentage was higher in the preterm group therefore is all the more significant.

The higher proportion of fat mass observed in preterm infants than in term newborns may actually simply be the mirror image of the lower amount of lean body mass of preterm infants. In neonatal intensive care units, the failure to implement the recommended dietary intakes in the 1st weeks of life $\mathrm{f}^{(10)}$ and the difficulties in estimating the high rates of energy expenditure of premature babies near discharge $^{(11)}$ could explain the lack of accretion of lean body mass in preterm population.

Among full-term infants, lean body mass was higher in males than in females. This is consistent with the literature ${ }^{(12,13)}$. Sex differences in body composition are primarily attributed to the action of sex steroid hormones in utero ${ }^{(13)}$. In utero testes produce testosterone, which is assumed to enhance lean body mass in fetal life. In male infants, during the 1st weeks of life, testosterone increases considerably and increases to the range of concentrations reached in adult men ${ }^{(14)}$, whereas ovaries remain relatively quiescent regarding oestrogen production, and do not secrete significant amounts of testosterone during perinatal development.

In contrast, among preterm infants, no significant difference was observed in the percentage lean body mass according to sex, due to a lower lean body mass in preterm males.
The relative lack of lean body mass observed in preterm boys, compared with full-term boys, is surprising as androgen secretion is known to be higher in preterm infants ${ }^{(15)}$. Numerous factors could contribute to the difference in lean body mass accretion between intra- and extra-uterine lives. Preterm males are known to be more severely ill than females during hospitalisation $^{(16)}$, and thus nutritional support could be less optimal in boys than girls, as was observed in the present study. In addition, although Forest et al. ${ }^{(14)}$ found no difference in plasma cortisol levels between male and female preterm infants, cortisol could contribute to the increased nutritional risk in male preterm infants if boys are exposed to a higher degree of stress in neonatal life ${ }^{(8,9)}$. Preterm boys may thus be exposed, not only to the cumulative nutrient deficit commonly experienced during the first few weeks of postnatal life, but also to higher levels of stress-induced cortisol secretion. Elevated cortisol may in turn elicit higher rates of protein breakdown and energy expenditure, and lower rates of protein synthesis, precluding optimal lean body mass accretion.

\section{Conclusion}

Compared to term infants, preterm infants have a higher percentage of fat mass, presumably because of a lesser accretion in lean body mass, particularly in preterm boys.

\section{Acknowledgements}

There is no conflict of interest. L. S. was supported, in part, by fellowship grants from the 'Société Française de Pédiatrie' (French Society of Pediatrics) and the 'Groupe Francophone d'Hépato-Gastroentérologie et Nutrition Pédiatrique' (French Speaking Group of Pediatric Hepato-Gastroenterology and Nutrition). A. C.-F., D. D. and J.-C. R. contributed to the study design; L. S., P. B., A. L. and A. C.-F. to the acquisition of data; L. S., P. B., D. D., A. L., J.-C. R. and A. C.-F. to the analysis and interpretation of data. Statistical analysis was performed by J.-C. R. and A. L. The manuscript was drafted by L. S., A. C.-F., D. D. and J.-C. R. and critically revised by all the authors. J.-C. R., A. C.-F. and D. D. were in charge of the overall supervision of the study.

\section{References}

1. Fomon SJ (1967) Body composition of the male reference infant during the first year of life. Pediatrics 40, 863-870.

2. Hawkes CP, Hourihane JO, Kenny LC, et al. (2011) Genderand gestational age-specific body fat percentage at birth. Pediatrics 128, E645-E651.

3. Koo WW, Walters JC \& Hockman EM (2000) Body composition in human infants at birth and postnatally. J Nutr 130 2188-2194.

4. Hovi P, Andersson S, Eriksson JG, et al. (2007) Glucose regulation in young adults with very low birth weight. $N$ Engl J Med 356, 2053-2063.

5. Barker DJ (2004) The developmental origins of adult disease. J Am Coll Nutr 23, Suppl. 6, S588-S595. 
6. Leunissen RW, Oosterbeek P, Hol LK, et al. (2008) Fat mass accumulation during childhood determines insulin sensitivity in early adulthood. J Clin Endocrinol Metab 93, 445-451.

7. Ellis KJ, Yao M, Shypailo RJ, et al. (2007) Body-composition assessment in infancy: air-displacement plethysmography compared with a reference 4-compartment model. Am J Clin Nutr 85, 90-95.

8. Ramel SE, Gray HL, Ode KL, et al. (2011) Body composition changes in preterm infants following hospital discharge: comparison with term infants. $J$ Pediatr Gastroenterol Nutr 53, 333-338.

9. Roggero P, Gianni ML, Amato O, et al. (2009) Is term newborn body composition being achieved postnatally in preterm infants? Early Hum Dev 85, 349-352.

10. Embleton NE, Pang N \& Cooke RJ (2001) Postnatal malnutrition and growth retardation: an inevitable consequence of current recommendations in preterm infants? Pediatrics 107, 270-273

11. Guilfoy VM, Wright-Coltart S, Leitch CA, et al. (2008) Energy expenditure in extremely low birth weight infants near time of hospital discharge. J Pediatr 153, 612-615.
12. Andersen GS, Girma T, Wells JC, et al. (2011) Fat and fat-free mass at birth: air displacement plethysmography measurements on 350 Ethiopian newborns. Pediatr Res 70, 501-506.

13. Hull HR, Dinger MK, Knehans AW, et al. (2008) Impact of maternal body mass index on neonate birthweight and body composition. Am J Obstet Gynecol 198, 416e1-416e6.

14. Forest MG, de Peretti E \& Bertrand J (1980) Testicular and adrenal androgens and their binding to plasma proteins in the perinatal period: developmental patterns of plasma testosterone, 4-androstenedione, dehydroepiandrosterone and its sulfate in premature and small for date infants as compared with that of full-term infants. J Steroid Biochem 12, $25-36$.

15. Kuiri-Hanninen T, Seuri R, Tyrvainen E, et al. (2011) Increased activity of the hypothalamic-pituitary-testicular axis in infancy results in increased androgen action in premature boys. J Clin Endocrinol Metab 96, 98-105.

16. Lee HC, Green C, Hintz SR, et al. (2010) Prediction of death for extremely premature infants in a population-based cohort. Pediatrics 126, E644-E650. 